\title{
LIGHT LITHOPHILE ELEMENT (BORON, LITHIUM) ABUNDANCES \\ IN THE VALLES CALDERA, NEW MEXICO, VC-1 CORE HOLE
}

\author{
Michael D. Higgins ${ }^{1}$
}

Department of Geology, McMaster University, Hamilton, Ontario, Canada

\begin{abstract}
Boron and lithium abundance distributions are very different in the sedimentary and volcanic sections of the VC-1 core hole, Valles caldera, New Mexico. In the sedimentary section the wide variations in boron and lithium abundances probably reflect both diagenesis and introduction of these elements in early hydrothermal fluids. Late, higher-temperature fluids appear to have leached boron and lithium from some rocks adjacent to fault zones and aquifers. The correlation of boron with lithium suggests that these elements behave in similar ways during diagenesis and hydrothermal alteration. The small variation of boron and lithium abundances in most of the vitreous volcanic rocks from the upper part of the core implies that their source was relatively homogeneous. Following primary devitrification, boron appears to have been stable, but lithium was mobile. Boron may have been stabilized by the development of boron-bearing submicroscopic phenocrysts in the lavas, or boron may be less soluble than lithium in relatively cool groundwater.
\end{abstract}

\section{Introduction}

The geochemistry of the light, lithophile elements lithium and boron has been somewhat neglected until recently, in part due to difficulties in the analysis of boron at the low levels commonly encountered in many rocks. In this study an unusual nuclear technique, Prompt Gamma Neutron Activation, has been used for the analysis of boron, while lithium has been analyzed by atomic absorbtion spectroscopy.

Valles caldera has been a major target of the U.S. continental scientific drilling program, and core hole VC-1 is the first hole completed under this program (Figure 1). One of the major objectives of VC-1 was to penetrate a high-temperature hydrothermal outflow plume near its source [Goff et al., 1986]. The core hole thus provides a unique opportunity to examine the relationship of boron and lithium in different rock types in an active hydrochermal environment.

The top $330 \mathrm{~m}$ of the hole penetrates intracaldera flows, tuffs, and interstratified sediments deposited in the moat of the caldera (Figure 2). All the volcanic rocks penetrated by VC-1 are less than 0.6 m.y. old [Geissman, this issue]. The volcanic rocks are relatively fresh, except for patchy devitrification and minor, low-temperature alteration in the middle VC-1 tuff, associated with a fault zone. High-temperature hydrothermal alteration is absent.

Two clay-rich units occur near the center of the core hole: a volcaniclastic breccia at the bottom of the volcanic sequence and in the underlying Permian Abo formation (Figure 2). These zones appear to associated with major fractures.

In contrast to the volcanic rocks, the underlying sediments show abundant evidence of faulting and shearing. They have been lightly to severely altered and mineralized by high-temperature hydrothermal fluids, especially along fractures.

Samples were taken at more or less regular intervals throughout the core, except where a unit would have been missed. No attempt was made to sample altered zones more intensively than other parts of the section.

\footnotetext{
${ }^{1}$ Now at Sciences de la terre, Universite du Quebec a Chicoutimi, Chicoutimi, Quebec, Canada.

Copyright 1988 by the American Geophysical Union.

Paper number 7B7046

0148-0227/88/007B-7046S05.00.
}

\section{Mechods}

Boron was analyzed using Prompt Gamma Neutron Activation. This method utilizes the nuclear reactions

$$
10_{\mathrm{B} \text { (n,alpha) }}{ }^{7} \mathrm{Li} *{ }^{7} \mathrm{Li}^{*} \text { (gamma) }{ }^{7} \mathrm{Li}
$$

Two grams of powdered sample are packed in a $1-\mathrm{cm}$-diameter teflon tube and irradiated in a flux of $2 \times 10^{7}$ neutrons per second at the McMaster Nuclear Reactor. The characteristic gamma rays (478 keV) emitted by these reactions during the irradiation are counted using an intrinsic Ge detector. Boron was determined with reference National Bureau of Standards standard 1571, for which boron $=33 \mathrm{ppm}$. Precision as determined by replicate analyses of samples is estimated to be $\pm 3 \%$. U.S.Geological Survey standard rock RGM-1 gives a value of boron $=27.8 \mathrm{ppm}$, which is closely comparable with that obtained by other researchers [Higgins, 1984]. For further details of the method see Higgins et al., [1984].

Lithium was determined using atomic absorption Spectroscopy with reference to chemical standards. One gram of each sample was dissolved in $\mathrm{HF}+\mathrm{HNO}_{3}+\mathrm{HClO}_{4}$, diluted to $100 \mathrm{~mL}$ and run in an acetylene-air flame. Precision is estimated to be $\pm 5 \%$.

\section{Results and Discussion}

\section{Brecaldera Sedimentary Rocks}

The lower $524 \mathrm{~m}$ of the core comprises principally Palaeozoic sedimentary rocks: The Pennsylvanian Madera limestone and Sandia formations; and the Permian Abo formation (Figure 2) and possibly the Mississippian Esprito Santo and Log springs formations [Hulen and Nielson, this issue]. A thin interval of Precambrain gneiss was also intersected by the core hole.

Diagenetic alteration is pervasive throughout the sedimentary section. Smectite-illite is an important diagenetic mineral [Keith, this issue] especially as it is known to host boron and lithium (reviewed by Bergeron, [1985]). The first stage of hydrothermal alteration was confined to fractures and intergranular space in the more permeable layers where chlorite, calcite, some pyrite and some additional smectiteillite were deposited from fluids at approximately $200^{\circ} \mathrm{C}$ [Keith, this issue]. Later stages of alteration were confined to zones of high permeability in the Sandia formation and the upper part of the Madera limestone. The fluids were at $275^{\circ}-300^{\circ} \mathrm{C}$ [Keith, this issue] and did not deposit any minerals likely to host boron and lithium.

Within the sedimentary section, boron and lithium abundances vary widely (0.7-56 ppm and 6.5-249 ppm respectively, Table 1 and Figure 3). Boron abundances are positively correlated to lithium abundances with a correlation coefficient of 0.60 (Figure 4). A correlation coefficient for a group of 13 samples greater than 0.53 is considered significant. The correlation between boron and lithium abundances suggests that their behavior is geochemically similar in low- and medium-temperature environments. Liule work has been done on boron and lithium correlations in sedimentary rocks elsewhere. However, these elements are well correlated in extremely altered seafloor basalts [Thompson and Melson, 1970]. In contrast, Bergeron [1985] found no correlation in basalts with lower degrees of alteration.

There is no simple relationship between depth and boron, lithium abundances, as is to be expected in a complex system. The most likely host for boron and lithium is smectite-illite, which is present 


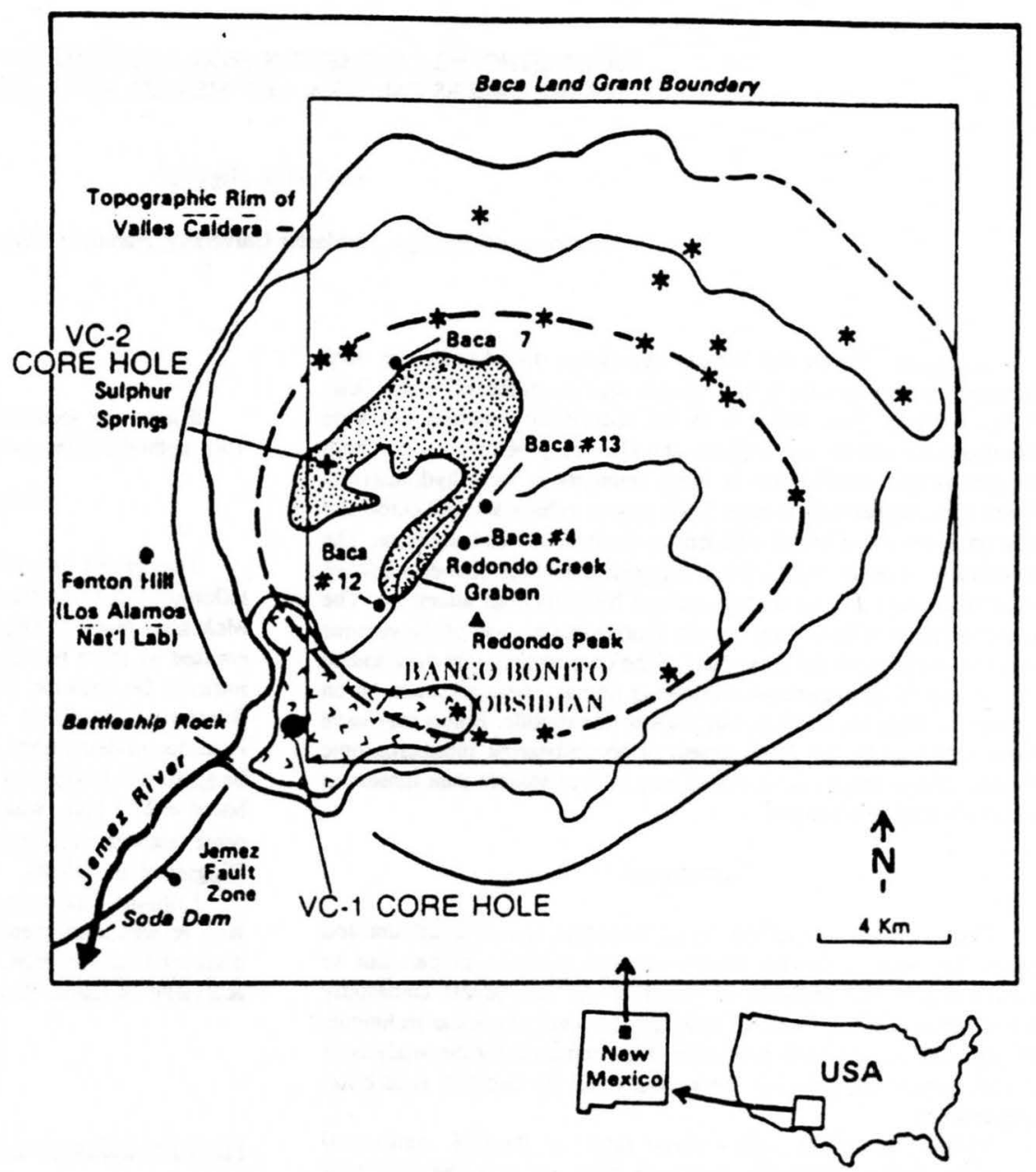

Fig. 1. Location map of Valles caldera and VC-1 core hole site.

throughout the sedimentary section. Samples low in boron and lithium at $546 \mathrm{~m}$ and $307.8 \mathrm{~m}$ are adjacent to an aquifer at $539 \mathrm{~m}$ [Goff et al., 1986] and fault zone af $318 \mathrm{~m}$ [Goff et al., 1986]. Circulating high temperature fluids $\left(275^{\circ} .300^{\circ} \mathrm{C}\right)$ may have partially broken down the clay minerals and leached boron and lithium from the system.

It is difficult to compare the overall abundances of boron and lithium found in this study with that similar sedimentary rocks elsewhere because of the scarcity of data and lack of control over its quality. However, a literature survey [Harder, 1974; Steinnes et al., 1974] indicates that boron abundances are similar to those of nonmarine sediments elsewhere, whereas lithium appears to be enriched (Table 1 and Figure 4). The mobility of lithium alone in this section is not consistent with the observed correlation of boron and lithium; therefore it is likely that the "bench mark" data are incorrect. Boron was formerly analyzed by emission spectroscopy. Work in our laboratory suggests that this technique tended to overestimate boron abundances. If boron abundances in typical sedimentary rocks are indeed lower, then both boron and lithium must have beeen introduced by circulating hydrochermal fluids.

The minimum overall fluid/rock ratio for the sedimentary section may be calculated as follows: The concentration of boron and lithium in the fluids is assumed to be the same as that of present-day hydrothermal fluids in the area $(B=15 \mathrm{ppm}, \mathrm{Li}=25 \mathrm{ppm}$ [Keith, 1986]). The original boron and lithium content of the rocks is assumed to be the same as that of the continental crust ( $B=9.2 \mathrm{ppm}, \mathrm{Li}=22 \mathrm{ppm})$ as estimated from the composition of the Canadian shield by Shaw et al., [1986]. These data were used in preference to the abundances in sedimentary rocks as the boron data was known to be reliable. The mean boron and lithium contens of the sedimentary rocks in this section, 22.4 and $107 \mathrm{ppm}$ (Table 1) then give minimum fluid/ro ratios of 0.9 and 3.4 respectively. These values are much lower th those indicated for the Yellowstone system [Sturchio et al., 1981 They are probably underestimates as it is unreasonable to assume th soluble elements such as boron and lithium could be entire precipitated out of hydrothermal fluids into a rock

\section{Postcaldera Volcanic Rocks}

The sedimentary formations are overlain by a thin volcanic brece the clay-rich parts of which are rich in boron and lithium. In 1 remainder of the volcanic sequence, boron and lithium show a mu smaller range of abundances as compared with the precalde sedimentary rocks (Figures 3 and 5). Four samples from the Midi VC-1 tuff, which overlies the breccia, have almost constant bor abundances (10.0-11.4 ppm). In contrast, lithium is more abundant the devitrified samples $(80,81 \mathrm{ppm})$ than the glassy samples $(61$, $\mathrm{ppm}$, Figures 5 and 6 ). Within the next three overlying formatic (Upper VC-1 tuff, VC-1 thyolite, and Battleship Rock wuff), boron a lithium show some variation, but the numbers of samples analyz from each unit are insufficient to indicate any trends.

The uppermost eight samples of the core are from the Ban Bonito obsidian, the youngest volcanic unit in the Valles caldera ( 0 . Ma). Vitreous samples show relatively little variation in boron a lithium (9.9-13.0 ppm and 59-68 ppm, respectively), which may accounted for by magmatic processes, such as fractional crystallizati Devitrified samples have similar boron contents to the vitreous samp but much lower lithium abundances (20-42 ppm). This behav 
VC-1 STRATIGRAPHY

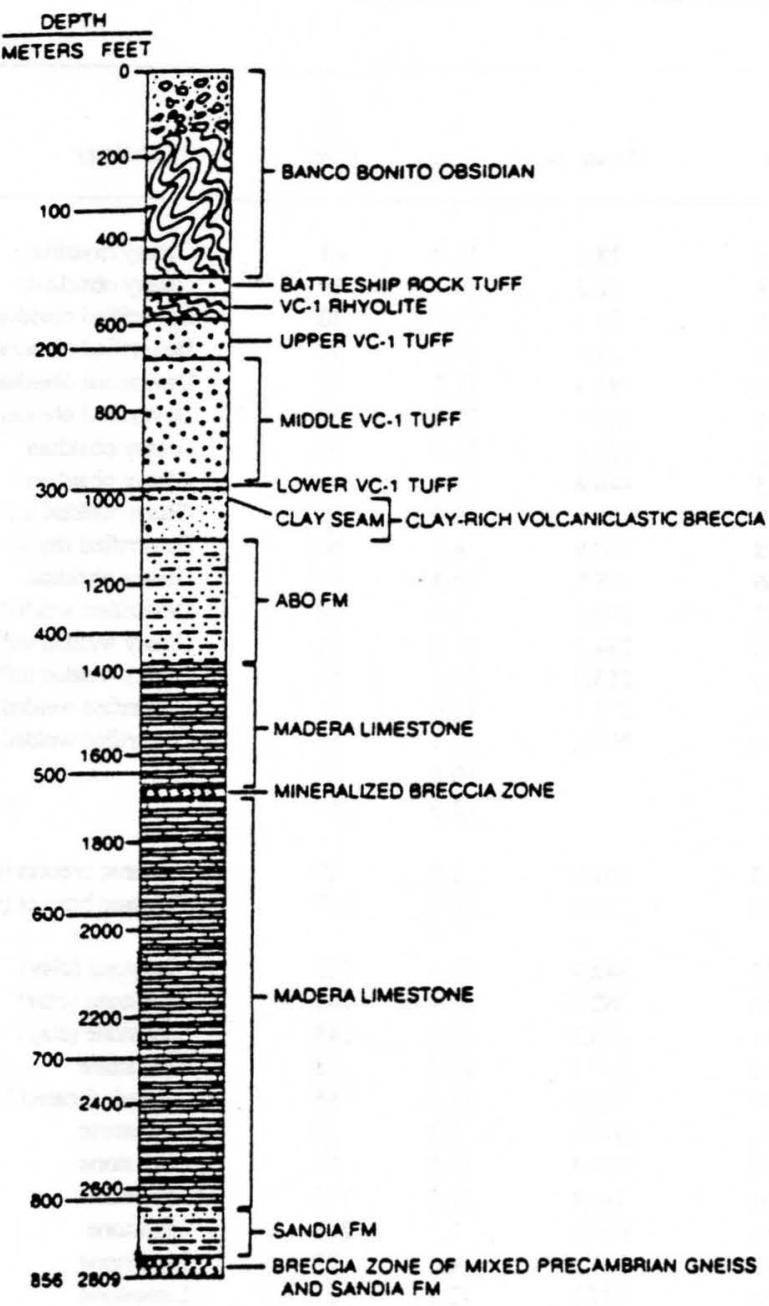

Fig. 2. Stratigraphic section of core hole VC-1.

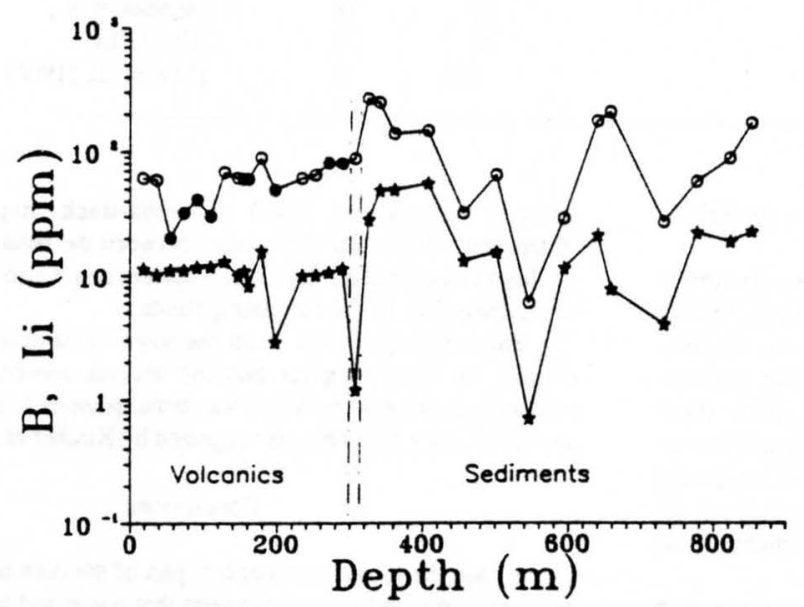

Fig. 3. Variation of boron (bottom line, asterisks) and lithium (top line, circles) with depth in the VC-1 hole. In the volcanic section, solid symbols indicate devitrified samples, and open symbols are vitreous samples. There is a volcanic breccia unit in between the volcanic and sedimentary sections of the core hola.

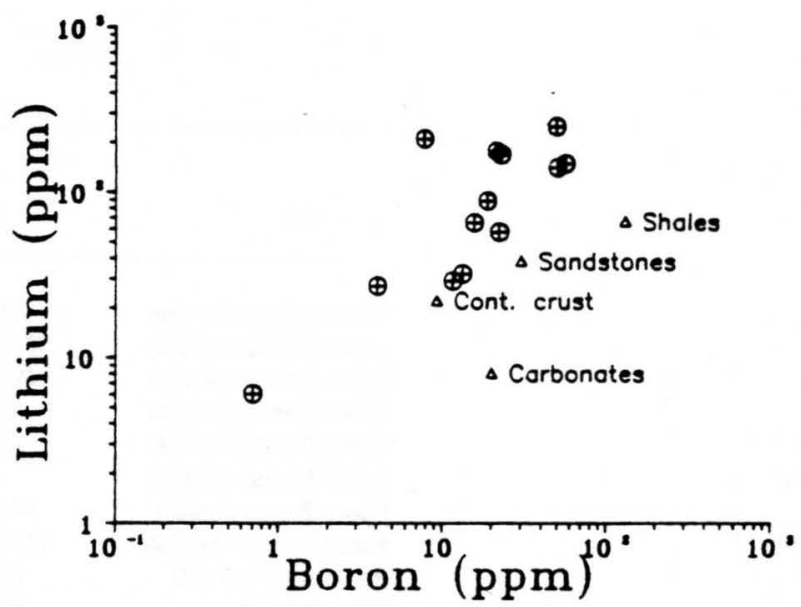

Fig. 4. Boron and lithium variations in the sedimentary rocks.

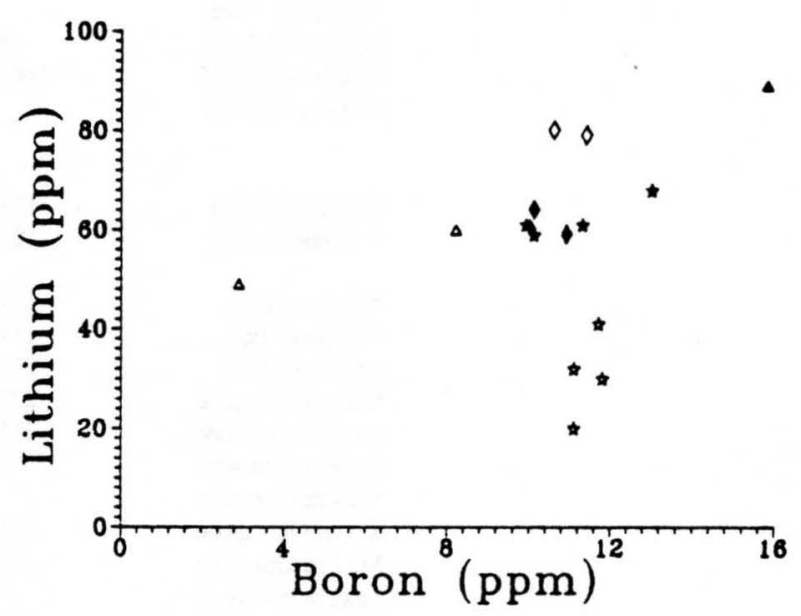

Fig. 5. Boron and lithium variations in the volcanic rocks (excluding the volcanic breccia). Asterisks are samples from the Banco bonito formation, Diamonds are from the Middle VC-1 tuff, and triangles are other samples. Solid symbols are vitreous samples, open symbols are devitrified.

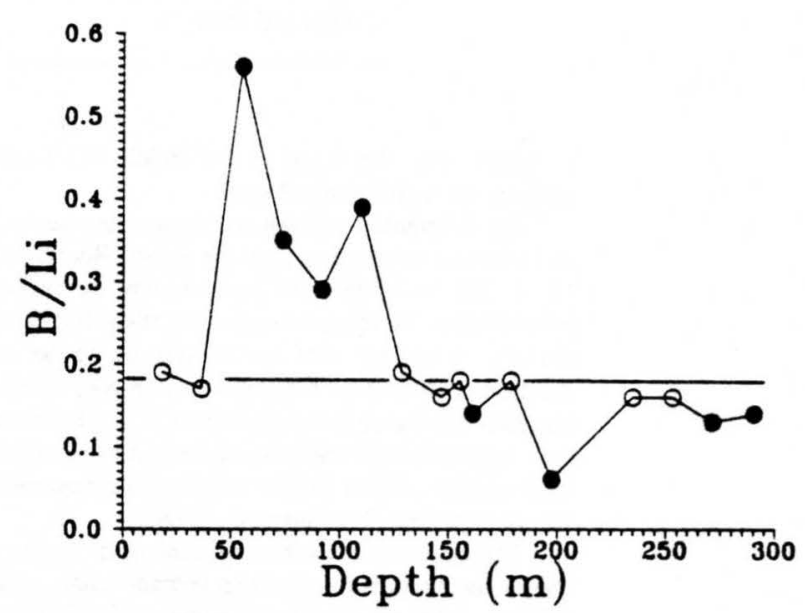

Fig. 6. Variation of boron/lithium ratios with depth in the volcanic section of the core hole. Open symbols are vitreous, solid symbols are devirified. 
TABLE 1. Analytical Dan, VC-1 Samples

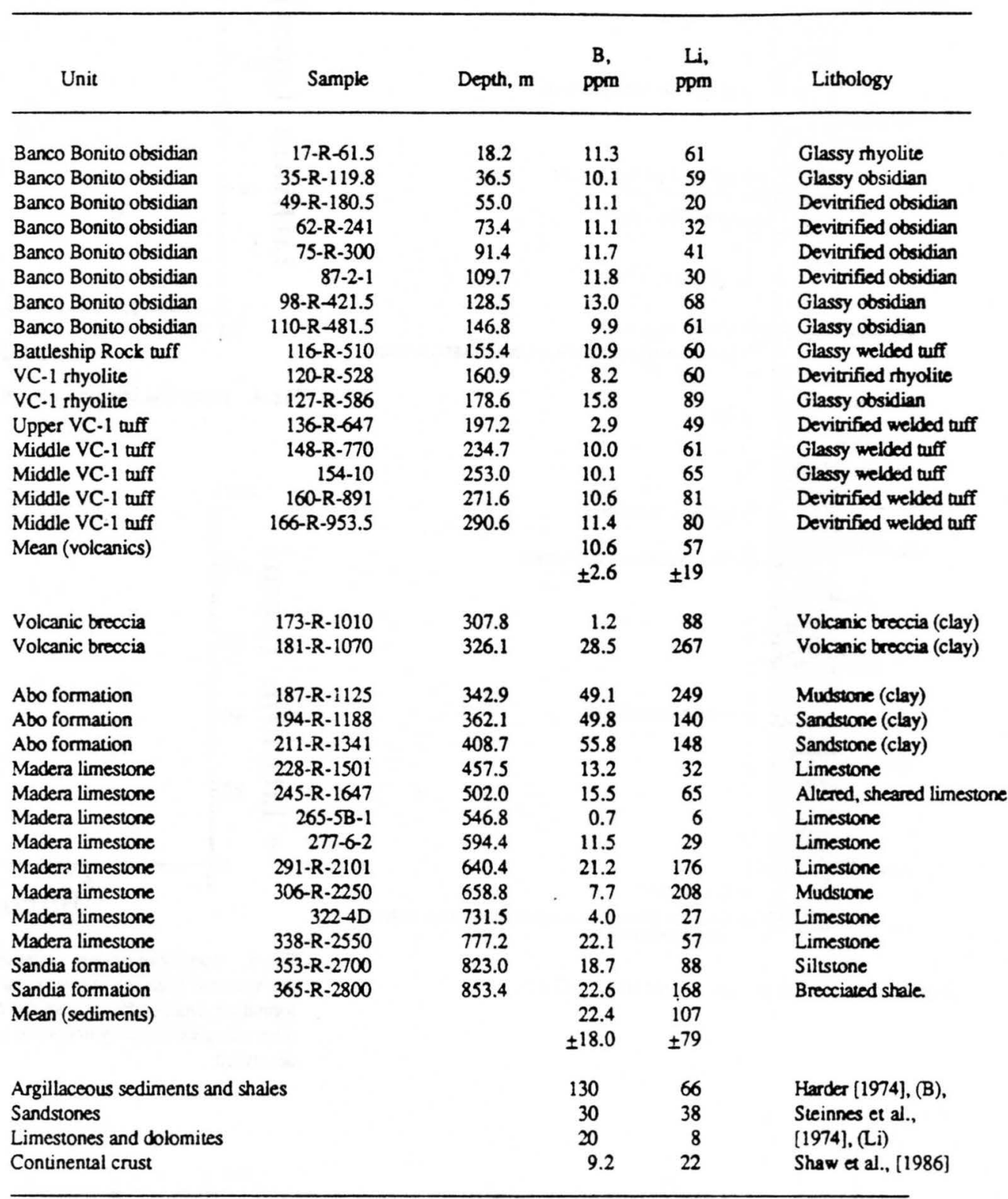

constrasts with that found in the Middle VC-1 tuff where devitrified samples are enriched in lithium.

The differences in boron and lithium abundances between devitrified and vitreous samples in both the Banco Bonito obsidian and Middle VC-1 tuff indicate that lithium may be mobilized by shallow groundwater at temperatures less than $100^{\circ} \mathrm{C}$ following primary devitrification but that boron appears to be stable under these conditions. Possibly, lithium was removed from the Banco Bonito obsidian and added to the Middle VC- 1 tuff by the action of circulating low-temperature groundwater in the caldera moat zone. Similarly, in the Yellowstone caldera, lithium is one of the most mobile elements in the altered rhyolites [Sturchio et al., 1986].

The behavior of boron and lithium in this system contrasts with that of the rhyolites in the Inyo volcanic chain, where both boron and lithium were mobilized following devitrification [Higgins, 1988]. Perhaps boron has been immobilized in the Valles caldera rhyolites by the development of submicroscopic crystals of a boron-bearing phase, such as tourmaline. However, suitable minerals have not been observed using a microscope, XRD or alpha-track mapping technique: [Carpenter, 1972]. The differences between the behavior of boron at is the Inyo volcanic chain and Valles caldera could also reflect difference: in the chemistry of the circulating fluids.

Boron/lithium ratios in all the vitreous samples all very simila (Figure 6). This suggests that the magma source for all the moa volcanics penetrated by VC-1 was homogeneous in lithium and boron as well as other elements, as suggested by Kircher et al. [this issue].

\section{Conclusions}

Within the lower, sedimentary part of the core hole the correlation between boron and lithium suggests that boron and lithium behave in: similar way during low- and medium-temperature geochemica processes. Overall boron and lithium have probably been introducec into this section by early hydrothermal fluids. Late, higher-temperaturn fluids have leached boron and lithium from fault zones and aquifers.

In the volcanic section there is little variation in boron and lithiur 
abundances in the vitreous samples. However, lithium appears to have been mobilized following primary devitrification. Lithium was probably transported in the system by circulating, cool groundwater (less than $100^{\circ} \mathrm{C}$ ) in the caldera moat zone. Boron may have been stabilized in the volcanic rocks by the development of boron-bearing submicroscopic phenocrysts. Alternatively, boron may be much less soluble than lithium in the relatively cool fluids that circulated in the moat zone.

Acknowledgements. I would like to thank my collegues in the "Boron project" Marilyn Truscott, Mario Bergeron, and Denis Shaw, for much heip. Fraser Goff carefully read the manuscript. This project was funded by an NSERC (Canada) grant to D. M. Shaw. McMaster Nuclear, Isotopic and Geochemical Studies group contribution 156.

\section{References}

Bergeron, M., Le comportement du bore dans la lithosphère océanique, Ph.D. thesis, McMaster Univ., Hamilton, Ont., Canada, 1985.

Carpenter, B. S., Determination of trace concentrations of boron and uranium in glass by the nuclear track technique, Anal. Chem., 44 . $600-602,1972$.

Geissman, J., Paleomagnetism and rock magnetism of quaternary volcanic rocks and late paleozoic strata, VC-1 core hole, Valles caldera, New Mexico, with emphasis on remagnetisation of late Paleozoic strata, L. Geophys. Res., this issue.

Goff, F., J. Rowley, J. N. Gardner, W. Hawkins, S. Goff, R. Charles, D. Wachs, L. Maassen, and G. Heiken, Initial results from VC-1, first continental scientific drilling program hole in Valles caldera, New Mexico. L. Geophys, Res. 21(B2), 1742-1752, 1986.

Harder, H., Handbook of Geochemistry, Vol. II-I, edited by K. A. Wedepohl, chapter 5, Springer-Verlag, New York, 1974

Higgins, M. D., Abundance of boron in international geochemical standards by Prompt-gamma neutron activation analysis, Geostand. Newsl., 8. 31-34, 1984.

Higgins, M. D., Trace element geochemistry of the Inyo volcanic chain, California: Evidence for multiple magma sources, magma mixing and post-eruption loss of boron, L Volcanol. Geotherm. Res, in press, 1988.

Higgins, M. D., M. G. Truscott, D. M. Shaw, M. Bergernon, G. H. Buffet, J. R. D. Copley, and W. V. Prestwick, Prompt-gamma neutron activation analysis at McMaster University Reactor, in Use and Deveiopment of Low and Medium Elux Nuclear Reactors. Broceedings of an International Symposium. At energie Kerntech. edited by O. K. Harling, L. Clark and P. von der Hardt. vol. 44 supplement, pp 690-697, Karl Thiemig, Munchen, Germany, 1984.
Hulen, J. B. and D. L. Neilson, Hydrothermal alteration in the Baca geothermal system, Redonde dome, Valles caldera, New Mexico. L Geophys. Res, 21, 1867-1886, 1986.

Hulen, J. B., and D. L. Neilson, Hydrothermal brecciation in the Jemez fault zone, Valles caldera, New Mexico: Results from CSDP core hole VC-1, L. Geophys, Res, this issue.

Keith, T. E. C., Hydrothermal alteration in the Madera limestone and Sandia formation from core hole VC-1, Valles caldera, New Mexico (abstract), Eos Trans. AGU. 66, 1080, 1985.

Keith, T. E. C., Alteration in the Madera limestone and Sandica formation from core hole VC-1, Valles caldera, New Mexico. L Geophys, Res, this issue.

Kircher, D., S. Self, and J. A. Wolff, Volcanology and preliminary petrology of the El Cajete series, Valles caldera, New Mexico. L Geophys. Res, this issue.

Shaw, D. M., J. J. Cramer, M. D. Higgins, and M. G. Truscott, Composition of the Canadian Precambrain shield and the continental crust of the earth. The Nature of the Lower Continental Crust, edited by J. B. Dawson, D. A. Carswell, J. Hall and K. H. Wedepohl, Geol. Soc. London Spec. Publ. 24, 275-282, 1986.

Steinnes, E., K. S. Heier and G. K. Billings, Handbook of Geochemistry, Vol.II-I, edited by K. A. Wedepohl, chap. 3, Springer-Verlag, New York, 1974.

Sturchio, N. C., K. Muehlenbachs and M. G. Seitz, Element redistribution during hydrothermal alteration of thyolite in an active geothermal system.: Yellowstone drill cores Y.7 and Y-8, Geochim. Cosmochim. Acta, 50, 1619-1632, 1986.

Thompson, G., and W. G. Melson, Boron contents of serpentinites and metabasalts in the oceanic crust: Implications for the boron cycle in the oceans. Earth Planet. Sci.Lett. 8, 61-65, 1970.

Truesdell, A. H. and C. J. Janik, Reservoir processes and fluid origins in the Baca geothermal system, Valles caldera. New Mexico, $L$ Geophys. Res., 21, 1817-1833, 1986.

White, A. F. Chemical and isotopic characteristics of fluids within the Baca geothermal resevoir, Valles caldera, New Mexico. L. Geophys. Res.. 21, 1855-1866, 1986.

M. D. Higgins, Sciences de la Terre, Universite du Quebec a Chicoutimi, 555, boulavard de l'universite, Chicoutimi, Quebec, Canada, G7J 2B1.
(Received March 2, 1987: revised October 29, 1987; accepted November 23, 1987.) 